\title{
Research on Teaching Reform of Engineering Ethics under the Background of Discipline Merging
}

\author{
Shasha Zhang \\ Wuhan University of Technology, Wuhan, 410205, China
}

Keywords: Engineering ethics, Teaching reform, Discipline merging

\begin{abstract}
Engineering ethics is not only the study of moral judgments, moral conflicts and moral decisions involved in engineering practice, but also the unique professional ethics and personal ethics that engineers must possess. Under the background of the integration of engineering and ethics, this paper puts forward some suggestions, such as improving the curriculum system, popularizing case teaching and expanding academic communications to provide some references for the relevant researchers.
\end{abstract}

\section{Introduction}

Engineering practice is a comprehensive reflection of the value relationship between mankind and nature and mankind and society, showing the dual characteristics of natural and social attributes. Engineering activities are closely related to the human beings. Various projects permeate with the value of human own judgments from the plan, organization, implementation to operation and a series of processes. For a long time, under the guidance of utilitarian values, the ethical problems caused by various types of projects have become increasingly prominent. The problems come one after another, including the excessive demand for natural resources, the continued deterioration of environmental pollution, the extreme imbalance of the ecological environment, the serious challenge to social security and social justice, and many other problems. Especially, the engineering activities which have produced great destructive and even disastrous consequences have prompted people to begin to reflect on the engineers as the main part of the engineering activities. A university should not only pay attention to professional skills no longer meet the development needs of the times, but also should focus on students' professional skills at the same time to strengthen the occupation ethics for the future engineers. It is necessary to add the education of engineering ethics in cultivating engineering talents in it. As one of the main source of cross disciplinary growth and application of modern academic research, it not only shows the academic development inevitable trend, but also has become the exploration of contemporary vision must focus on engineering ethics education theory and practice. In the face of world economic globalization, cultural diversity, ecological benefits and the internationalization of education background. The engineering ethics education must keep pace with the times, actively absorbing the theory of knowledge of other subjects and the latest research results to expand the space for development to enrich the education content and boost the scientific development.

\section{Discipline Merging in Engineering Ethics Education}

Integration of Engineering Technologies and Social Security. Ethical issues in engineering ethics is engineering activity itself involved, which is generated and used to bind and regulate the engineering behavior. It also controls the relationship between inside and outside of the ethical spirit, moral norms and values in engineering activities. It is not only a kind of behavior norm that regulates the internal and external relation of engineering technology activity, but also is a kind of practice spirit that the main body grasps engineering technology activity. Therefore, technical ethics is a kind 
of ethical and ethical problems in human social practice, that is, the ethical value of the ethical problems in engineering and technological activities. For a long time, there has been a great deal of controversy about whether engineering technology activities are related to ethical factors, or whether moral evaluation and moral intervention should be carried out. Engineering technology activity is a process of interaction between technological system and external factors including ethical factors. Although engineering activities, as an activity of human nature reform, must obey and obey the laws of nature, and in this sense, engineering and technological activities do have certain autonomy. However, man is the subject of morality, and man has the freedom to make moral choice. In the final analysis, the technical activity is controlled by man, and it reflects the value of human desire. In engineering and technical activities, based on what kind of value target, what technical scheme is chosen is the result of human's free choice according to certain scale. The individual's choice of technical solutions and value goals means responsibility. Obviously, the engineering technology activity has the strong ethics implication. The technical development cannot depart from the moral intervention and the adjustment. The moral standard should become the engineering technical activity according to a basic appraisal standard.

Integration of Engineering Benefit and Social Equity. The interest relationship in engineering activities includes two aspects: the benefit relationship between different subjects within the project and the benefit relationship between the project and the external environment. The interests of different subjects within the project are reflected in the decision-making, planning, construction, supervision, acceptance and other stages and links of the engineering activities, which include the decision stage of engineering project, investors and the public revenue and impaired, different investors interests, other aspects of the project. It also includes the interest relationships between investors and managers, construction engineering and other different subjects. The relationship between engineering and external environment can be divided into two aspects: the relationship between engineering and social environment and the relationship between engineering and the natural environment. The implementation of a project can always bring direct benefits to some people and parts of society. As the engineering activities in the interests of the relationship is very complex, it can effectively coordinate the interests of all parties, to achieve the unity of efficiency and fairness. It has become an important evaluation standard of the engineering activities. The core issue is to solve the interests of engineering ethics. Efficiency and fairness are the two most basic principles of value in human economic life. Engineering activity, in a sense, is also an economic activity, and therefore, we must adhere to the two basic values of efficiency and equity. In the interests of the scope of engineering ethics, the efficiency of expression of engineering activities to realize the value, to measure a project in resource utilization efficiency, especially to reduce the project cost through technological progress and improve the efficiency and the level of. Therefore, maximizing economic benefits is an important basis for judging engineering activities.

Integration of Engineering Responsibility and Social Subject. The subject of engineering responsibility ethics not only includes the main body of engineering activities, but also includes all the participants inside and outside engineering activities. The main body of an engineering activity is an organized group or group, and the number of builders of a project is less than a few, and tens of thousands or even millions. The internal group staff have strict division of labor, such as occupation managers, investors, engineers and workers and so on to form engineering decision makers, designers, managers and implementers of various social roles in different engineering activities. The engineering occupation decision maker's duty is to determine the objectives and constraints engineering, grasp the progress of the project; the designer engineer is responsible to the project objectives and constraints to implement design; the main responsibility is the scheduling and management of personnel and supplies; the realizer's duty is to undertake the construction project operation. Among them, the engineer's professional responsibility is the key factor of engineering professional responsibility. It directly determines the quality and safety of the project. All the participants inside and outside the engineering activities, including political decision-makers, legal persons and citizens, are the subject of the project responsibility. They should shoulder the common responsibility of the project together with the main body of the engineering activities. Take 
environmental pollution caused by engineering activities as an example. The engineers are undoubtedly responsible for the environmental pollution caused by the engineering activities. But at the same time, engineers are not the only responsible subjects. Besides the engineers, the enterprises and the government also have corresponding responsibilities, and even have more important responsibilities. The limited company is the subject of engineering activities who should take on the engineering activity of its own, including employers, employees and public safety.

\section{Reform Directions of Engineering Ethics Education under the Background of Discipline Merging}

Improve Curriculum System. From the point of view of discipline, the effective development of engineering ethics education must rely on the establishment of related courses. At present, the teaching of engineering ethics knowledge in China's colleges and universities is mainly carried out through public courses or extended teaching of some knowledge points in relevant professional courses. Such courses and teaching models are not conducive to the independent development of engineering ethics education. Engineering ethics education should have its own curriculum and teaching arrangements, and the relevant curriculum system should be optimized. We should construct the curriculum model of "theory plus practice". Engineering ethics education is not only the theory education but also the practice education. It should not only teach the ethical theory of knowledge engineering to education through classroom teaching, but also through the investigation, visit the visit deepen education practice teaching of relevant theoretical knowledge to understand and grasp, cultivate and strengthen awareness of engineering ethics. The research group attaches great importance to the construction of teaching material system, widely absorbing domestic and international engineering ethics in the new theories and practices, constantly revised and improved, the completion of "series of textbooks, enrich and develop the teaching system of engineering ethics education in china. In the selection of teaching content, expounds the basic principle, a series of engineering ethics logic framework, focus on cultivating the students' ability to analyze and solve problems, implementation of engineering ethics textbook significant shift from single textbook to textbook series, from the use of theory teaching to the reading theory and case combination. The autonomy of the innovation and development of engineering ethics education does not mean rejecting the research results of related disciplines, but should be the theoretical basis of relevant and more basic subjects. Engineering ethics education is closely related to ethics, sociology, ecology, engineering, psychology and other disciplines. Teachers should make full use of these disciplines to consolidate the subject foundation of their own development.

Promote Case Teaching. Case teaching method is a new teaching method which is enlightening and practical, which can improve students' decision-making ability and comprehensive quality. In the practice of the case teaching model, the research group pays attention to the combination of research and teaching, and emphasizes the construction and implementation. It pays attention to the construction of typical case libraries, and pays attention to the appropriate policy issues of social policies and professional associations. On the one hand, we should actively absorb and draw on the classic case resources both at home and abroad, such as the Columbia disaster. On the other hand, teachers should deep excavation of the project industry typical case resources. Teachers can organize elective students according to the principles of similar majors, and each group should select a typical case of higher social concern related to their own major in combination with their own professional fields. From the point of view of engineering ethics perspective, students can select a positive case, showing engineers in this case the scientific spirit of seeking truth and related occupation ethics; it can be a negative example and analysis of engineering ethics criticism against moral principles, the destruction of the natural environment. Then, the teams sent their representatives to the other students in the class in an easy to understand language. The end of the show is scored by other students, followed by rewards from each team's score to improve student participation. In this series of activities, the students hand carding and analysis on the ethical problems of collecting information, choice and sorting out the data when involved in their professional and professional field. It guides 
the students to have a more in-depth understanding and thinking for the professional itself. On the other hand, for other professional students, listening to explain different professional students can enrich their own knowledge.

Strengthen Academic Communication. In the implementation of engineering ethics in the process of educational reform, we should actively absorb the international advanced experience of engineering ethics education, expand the international perspective, and actively participate in the international seminar. At the same time, we should also make full use of learning opportunities for academic exchange or visit. Through these high-level academic conferences, teachers and students can draw lessons from the teaching of engineering ethics, to promote the exchange of experience teaching, improve the teaching level of teachers and strengthen the understanding of the discipline merging. The university should regularly communicate with other enterprises and colleges to discuss the coordination direction of training objectives, credit assignment and teaching objectives of undergraduate students, to fully understand the direction of curriculum reform of engineering ethics. First, during the course selection, the university should set up a professional guidance group to help students to select courses, so that students can choose the right elective courses at the right time. The course selection team can be made up of professional teachers and senior students or graduate students. Secondly, the university should determine the reform orientation. The university should actively cooperate with enterprises and colleges. It can promote teachers to find the intersection between different disciplines and carry out cooperation and exchanges among other teachers. It provides a good development platform for the future teaching and research of engineering ethics education.

\section{Conclusion}

All projects have multiple objectives, such as maximum profit, best quality, shortest duration, environmental protection and safety. The optimal goal of a single target must be sacrificed at the expense of other goals. Therefore, engineering ethics involves the integration of several disciplines. In the context of engineering ethics education in China, only firmly grasping the main line of discipline integration, can we truly lead the engineering ethics education into the correct path.

\section{References}

[1] Wang Jin. Necessity of the Integration of Engineering and Ethics[J]. Journal of Engineering Management, 2015, 29(1): 23-27.

[2] Zhang Yong, Lv Cixian. On Innovation Development of Engineering Ethics Education Under the Background of Interdisciplinary Fusion[J]. Research in Higher Education of Engineering, 2016(3): 121-126.

[3] Dai Liang, Shi Yumin. The Diversified Visions of Engineering Ethics: The Characteristics of Mike W. Martin s Engineering Ethics and Enlightenment[J]. Journal of Kunming University of Science and Technology, 2016, 16(2): 10-17.

[4] Zhang Hengli, Zhao Yachao. Engineering Ethics: The Model of Interdisciplinary Collaborative Research [J]. Science and Technology Management Research, 2016(1): 262-266.

[5] Baillie C, Levine M. Engineering ethics from a justice perspective: A critical repositioning of what it means to be an engineer[J]. International Journal of Engineering, Social Justice, and Peace, 2013, 2(1): 10-20.

[6] Van der Loos H F M, Hurol Y. As a committee of the National Academy of Engineering recognized, ethics education should foster the ability of students to analyze complex decision situations and ill-structured problems. Building on the NAE's insights, we report about an innovative teaching approach that has two main features: first, it places the emphasis on deliberation and on 
self-directed, problem-based learning in small groups.[J]. Science and Engineering Ethics, 2014, 20(1): 261-276.

[7] Yahaghi J, Sorooshian S. The role of engineering ethics on concrete fire safety[J]. Science and engineering ethics, 2017: 1-2.

[8] Wilson W R. Using the Chernobyl incident to teach engineering ethics[J]. Science and engineering ethics, 2013, 19(2): 625-640. 